\section{Relationships of humans to chimps and gorillas}

SIR-The issues raised by Jared Diamond ${ }^{1}$ concerning the phylogeny of humans and the apes turn on the interpretation of very little data. Given that humans, chimps, and gorillas are closely related, which pair are most closely related? The evidence linking chimps to gorillas subsumes some genetic data, anatomical data and most studies of the chromosomes. The only ambiguities - which Diamond takes as unequivocal proof of a chimp-human phylogenetic bond, as opposed to a chimp-gorilla bond - seem to exist in the interpretation of a very few highly publicized molecular studies.

I wish to raise the possibility that Diamond may have been misled by genetic braggadocio. Genetic studies have consistently failed to resolve the closest relatives among human, chimpanzee and gorilla, which has been a continuing source of frustration to practitioners. Given the general lack of humility common in molecular biological studies, the field's achievements may occasionally be difficult to distinguish from its aspirations.

The important problem in interpreting all of these results is to gauge which are giving us phylogenetic history, and which are not. Obviously only some are; but by selectively and uncritically reporting conclusions we stand to gain little.

Diamond's first line of evidence for the human-chimp bond is the $\eta$-globin pseudogene region. Sequencing a stretch of about 7,100 nucleotides in each of the four taxa (Homo, Pan, Gorilla and Pongo), Miyamoto et al. ${ }^{2}$ located only eight with which to link humans and chimps. This was not many, but they properly recognized that it was more than the three they could find to link chimp and gorilla, or the three they found to link human and gorilla. The strength of these characters will have to outweigh two significant considerations. The first is homoplasy: there are, after all, only four nucleotides. The second is sequencing error, by which I do not impugn the technical competence of the authors, but rather note a widespread concern in the field ${ }^{3}$. Miyamoto et al., themselves, observe in footnote 31 of their paper that in sequencing the human DNA, they found 44 sites at which their sequence differed from another determined sequence of the same clone. Where every nucleotide synapomorphy counts - as in this case we need to be very circumspect about the basis upon which we rewrite our phylogenies. Superimpose upon this the spectre of nucleotide polymorphisms ${ }^{4}$, and I prefer the more conservative conclusion, that these sequence data are interesting, rather ambiguous (as are most of the other genetic data bearing on the problem) and have not felled the phylogenetic tree link- ing chimps and gorillas.

The second line of evidence adduced by Diamond is the DNA hybridization study of Sibley and Ahlquist ${ }^{5,6}$. That study, unfortunately, is still not fully documented. In my experience the melting profiles, per cent hybridizations, melting temperatures and even the analytical procedures on which Sibley and Ahlquist based their conclusions are not available to interested colleagues. Sibley and Ahlquist, since first publicizing their conclusions, have consistently failed to meet the burden of proof which falls upon all investigators. Until that burden is met, it is gratuitous to assume the interpretations are valid, or to draw conclusions from it.

Invoking Sibley and Alquist's conclusions, however, Diamond then proceeds from the proposition that humans are related to chimpanzees, to infer that humans actually are chimpanzees. Chimpanzees obviously have an intimate relationship of common ancestry with humans (and gorillas, which have been occasionally grouped as congeneric with chimps) but common ancestry is not identity. I may be my brother's keeper, but I am not my brother.

This absurd declaration is not the first such statement by a molecular advocate attempting to generalize the genetic similarity of humans, chimps and gorillas. In fact, Zuckerkandl ${ }^{7}$ deduced a quarter century ago that "from the point of view of haemoglobin structure, it appears that gorilla is just an abnormal human, or man an abnormal gorilla, and the two species form one continuous population".

Yet we are not our haemoglobin. Scientific progress entails distinguishing between hyperbole and description; between the literary and the literal - and not confusing one for the other. Is it possible that the molecular approach has not brought us as far in the past twenty-five years as is commonly thought?

Departments of Anthropology JON MARKS and Biology,

Yale University,

New Haven,

\section{Connecticut 06520, USA}

1. Diamond, J. Nature 332, 685-686 (1988)

2. Miyamoto, M. et al. Science 238, 369-373 (1987).

3. Orkin, S.H. Trends Genet. 3, 207 (1987)

4. Savatier. J. et al. J. molec. Evol. 24, 309-318 (1987).

5. Sibley, C. \& Ahlquist, J. J. molec. Evol. 20, 2-15 (1984).

6. Sibley, C. \& Ahlquist, J. J. molec. Evol. 26, 99-121 (1987)

7. Zuckerkandl, E in Classification and Human Evolution (ed. Washburn, S.L.) (Wenner-Gren, New York, 1963).

DIAMOND REPLIES-I discussed ${ }^{1}$ two issues: which pair among human, chimp and gorilla are each other's closest relatives; and the relative merits of DNA sequencing and DNA/DNA hybridization for deducing phylogenies. I agree with the reservations of Marks (and Filipski ${ }^{2}$ ) about DNA sequencing, and it was on the basis of some of the same points that I concluded by preferring DNA/DNA hybridization of the whole genome over sequencing of genome fragments as a phylogenetic method. But I disagree with Marks' comments about hominoid relationships.

Marks begins by stating that the only ambiguities in the weight of evidence linking chimps to gorillas are a very few moiecular studies. In fact, of course, the nonmolecular evidence is equivocal and diverse lines of molecular evidence show that human, chimp and gorilla are close but that human and chimp are slightly closer to each other than either is to gorilla. To previous molecular evidence ${ }^{3}$ based on mitochondrial DNA, DNA/DNA hydridization, $\eta$-globin pseudogenes, fibroblast polypeptides and immunoglobulin $\mathrm{E}$ pseudogenes, can be added recent data from a further eight kilobases of sequence ${ }^{4.5}$.

While Marks refers to the study of Sibley and Ahlquist as undocumented, these authors gave detailed descriptions of their methods in many earlier papers and presented their hominoid data in two lengthy papers, of which ref. 3 gives 514 DNA/DNA hybridization values. At Marks' urging, J. Powell and A. Caccone at a recent meeting of the Society for the Study of Evolution redetermined hominoid DNA/DNA hybridization values by a different method, using some samples provided by Sibley and Ahlquist as well as others obtained with Marks' help, and obtained results concordant with those of Sibley and Ahlquist $t^{3}$.

Finally, Marks attributes to me the inference that humans are chimpanzees, which he labels an absurd declaration. Instead, I noted that common chimps, pygmy chimps and humans are each other's closest relatives, and that the DNA differences among these three species are no greater than the differences among species assigned to the same genus in other animal groups ${ }^{6}$. Congeneric does not mean identical.

Physiology Department

JaRed M. Diamond

UCLA Medical School, Los Angeles, California 90024, USA

1. Diamond, J. Nature 332, 685-686 (1988)

2. Filipski, J. Nature 334, 571 (1988)

. Sibley, C.G. \& Ahlquist, J.E. J. molec. Evol. 26, 99-121 (1987).

Maeda, N. et al. Molec. biol. Evol. 5, 1-20 (1988)

5. Miyamoto, M. et al. Proc. natn. Acad. Sci. U.S.A. (in the press).

6. Diamond, J. Nature 310, 544 (1984)

\section{Scientific Correspondence}

Scientific Correspondence is intended to provide a forum in which readers may raise points of a scientific character. They need not arise out of anything published in Nature. In any case, priority will be given to letters of less than 500 words and five references. 